\title{
A crítica da crítica dos mestrados profissionais: uma reflexão sobre quais seriam as contradições mais relevantes
}

\section{Criticism of the professional masters: a reflection on what would be the most relevant contradictions}

\author{
Alexandre Maia do Bomfim ${ }^{1}$. Valéria Vieira ${ }^{1}$. Eline Deccache-Maia ${ }^{2}$
}

\begin{abstract}
Resumo: A proposta deste artigo é fazer uma crítica da crítica dos apontamentos realizados aos cursos de Mestrados Profissionais, partindo especialmente de um artigo intitulado "O protagonismo controverso dos mestrados profissionais em Ensino de Ciências", das pesquisadoras Rezende e Ostermann. Pretende-se prosseguir por um dos caminhos, deixados pelas autoras, o do diálogo. Não obstante, numa contra-argumentação de que o problema dos Mestrados Profissionais não está nos lugares que propuseram em seu artigo, mas em outros. Será necessário primeiramente apontar no estudo das autoras quais seriam as contradições da argumentação, para, por meio de uma pesquisa descritiva, ensaiar quais seriam os desafios mais centrais por que, segundo nossa avaliação, realmente passariam os Mestrados Profissionais. Palavras-chave: Mestrado profissional. Ensino de ciências. Educação básica. Formação de professores.
\end{abstract}

\begin{abstract}
The purpose of this article is to make a critical reflection of the comments made on Professional Masters courses, especially starting from an article entitled "The controversial role of the professional master's degrees in science education", by the researchers Rezende and Ostermann. It is intended to pursue one of the paths suggested by the authors, that of positive debate. In an opposite direction, the problems of the Professional Masters is not proposed in his article, but in others. The first point in this study explores what are the contradictions of the arguments for the Professional Masters, through descriptive research, in order to test what the challenges would be, which according to another assessment are those that really pass the Masters Professionals.
\end{abstract}

Keywords: Professional masters. Science education. Basic education. Teacher education.

\footnotetext{
${ }^{1}$ Instituto Federal de Educação, Ciência e Tecnologia do Rio de Janeiro (IFRJ), Rio de Janeiro, RJ, Brasil. E-mail: $<$ alexandre.bomfim@ifrj.edu.br>.

${ }^{2}$ IFRJ, Rio de Janeiro, RJ, Brasil. Orcid: <https://orcid.org/0000-0003-4770-3988>.
} 
A definição dominante das coisas boas de se dizer e dos temas dignos de interesse é um dos mecanismos ideológicos que fazem com que coisas também muito boas de se dizer não sejam ditas e com que temas não menos dignos de interesse não interessem a ninguém, ou só possam ser tratados de modo envergonhado ou vicioso (BOURDIEU, 1998, p. 35).

\section{Introdução}

Os argumentos que vamos desenvolver neste trabalho foram inspirados pelo artigo "O protagonismo controverso dos mestrados profissionais em Ensino de Ciências" assim como do Editorial intitulado "Os mestrados profissionais em ensino das ciências da natureza no Brasil”, ambos de autoria das pesquisadoras Flávia Rezende e Fernanda Ostermann. Esses dois textos foram apresentados na mesma edição da presente revista, referente aos meses de julho a setembro de 2015. Em linhas gerais, estamos propondo-nos a continuar o debate instalado por Rezende e Ostermann (2015) e Ostermann e Rezende (2015), buscando um outro caminho de crítica, inclusive compartilhando a nossa experiência com o Mestrado Profissional (MP).

O nosso Programa de Pós-graduação stricto sensu em Ensino de Ciências (Propec) teve início em 2008 com uma turma de MP (BRANDÃO; DECCACHE-MAIA; BOMFIM, 2013; ROÇAS et al., 2011) até sua ampliação ao Mestrado Acadêmico em 2014. Em julho de 2016 (data de referência para este estudo), o Programa estava em nossa nona turma e já com 71 egressos. Será, em parte, com uma breve pesquisa sobre esses egressos, que sustentaremos alguns de nossos argumentos.

\section{Nossos questionamentos às Críticas do Mestrado Profissional}

Antes de iniciarmos a crítica da crítica ${ }^{3}$, vale assinalar uma característica da Revista Ciência \& Educação (pelo menos para algumas de suas últimas edições). O editorial da revista pode não vir apresentando todos os artigos da edição ou mesmo não vir fazendo uma análise mais global. Foi o que aconteceu na edição de número 3 do volume 21, de 2015, em que as autoras

\footnotetext{
${ }^{3}$ Uma curiosidade, mas também um elemento importante à reflexão. Devemos dizer crítica a (alguma coisa) ou crítica de (alguma coisa)? Se formos considerar a língua portuguesa na atualidade, para a maior parte dos casos, seria critica a (alguma coisa), seguindo orientações oficiais (HOUAISS, 2016). Não obstante, se formos recorrer à tradição filosófica (especialmente a marxiana), seria crítica de (alguma coisa), como aconteceu nas obras "Crítica da razão prática” (de Kant), "Crítica da filosofia do direito de Hegel” (de Marx), "Para crítica da economia política" e, o mais conhecido de todos, "O capital: crítica da economia política" (de Marx), chegando mesmo até Jean Paul Sartre com seu livro "Crítica da razão dialética". Na tradição filosófica, a palavra "critica" traz muito de sua origem grega, se relaciona com separar, peneirar, escolher, reforçar alguns elementos e dispensar outros... Criticar, nesse sentido, é esmiuçar algo ao ponto da revelação, do conhecimento, ao ponto de fazer escolhas (conhecimento político). (Crítica da - funciona como análise da; Crítica a - funciona como uso corriqueiro de fazer referência direta a. O mesmo funciona para elogio - ver "Elogio da loucura" (Roterdam)).
} 
de um dos artigos, Rezende e Ostermann (2015), assinam também o editorial (OSTERMANN; REZENDE, 2015). Este se referiu sinteticamente ao artigo das próprias autoras e foi, de forma até mais contundente, crítico ao Mestrado Profissional como veremos.

Os dois textos se iniciam (OSTERMANN; REZENDE, 2015; REZENDE; OSTERMANN, 2015) criticando as influências da Organização para Cooperação e Desenvolvimento Econômico (OCDE) e do Banco Mundial (BM ou BIRD) ${ }^{4}$ e, ainda com um referencial reconhecidamente crítico, ressaltando a autora Acácia Kuenzer, estudiosa a cujas ideias, em princípio, também nos alinhamos. Contudo, ao final da leitura, foi possível perceber que, de todas as críticas possíveis de serem feitas aos MP, a escolhida pelas autoras foi, ao nosso ver, iconoclasta. Vamos aos nossos argumentos.

Após 19 anos de existência do MP estaria o artigo anacrônico? Entendemos que, na ausência de movimento anterior consistente, a iniciativa é bem-vinda e vale acolhermos o debate. Os mestrados profissionais foram instalados na portaria de número 80 de 1998 (CAPES, 1998). Assim, os textos poderiam ter feito um resgate histórico e ensaiar uma crítica diacrônica, mas isso não ocorreu. De qualquer forma, essa não contextualização histórica não foi o ponto de que mais divergimos da análise, mas sim o fato de hispostasiarem a questão. Vejamos no trecho transcrito:

[O mestrado profissional] [...] não consegue reverter a carência de professores da Educação Básica por não propiciar melhorias profissionais significativas e, também, porque a maioria dos professores egressos desses cursos não permanece na escola em que lecionava, migrando para o Ensino Superior ou para os Institutos Federais de Educação, Ciência e Tecnologia (OSTERMANN; REZENDE, 2015, p. I).

Primeiramente, exigir que o MP reverta a carência de formação dos professores da Educação Básica (EB) seria dar conteúdo absoluto ao que é relativo. Os MP teriam essa enorme tarefa? Para as autoras, a Coordenadoria de Aperfeiçoamento de Pessoal de Nível Superior (Capes) atribuiria esse papel aos MP. De acordo com a nossa interpretação, esse fato nos parece uma generalização nada frutífera. Seria necessário considerar que os elementos centrais dos problemas estão em outros lugares ou não estão exclusivamente num único lugar.

Uma outra contradição identificada foi apontar a proposta dos MP restringindo-a à formação continuada. Em tese, os mestrandos da modalidade profissional voltam à Academia para rever seu trabalho docente, mas, no fim das contas, não se apropriariam de elementos novos de uma área (no caso de Ensino), não apreenderiam novas teorias e/ou novas metodologias? E,

\footnotetext{
${ }^{4} \mathrm{Na}$ verdade, as autoras Resende e Ostermann (2015) e Ostermann e Rezende (2015) optam pela sigla BM, mas é mais recorrente fazer uso da sigla BIRD (Banco Internacional para Reconstrução e Desenvolvimento), que faz referência à parte do Banco Mundial que trata mais dos assuntos sociais e de reconstrução dos países.
} 
por outro lado, fazendo comparações aos Mestrados Acadêmicos (MA), nestes, também, muitos docentes não procurariam melhorar seu desempenho e refletir a própria prática profissional de magistério? Foi nesse lugar, que as autoras voltaram suas críticas à formação continuada, a favor da formação inicial, mas vieram com uma proposta bem controversa, a de Educação em serviço. A luta pela Formação Inicial rivaliza com a luta pela Formação Continuada? Uma exclui a outra? E educação em serviço, possuidora de um apelo extensionista, possuiria conteúdo e potencial de prática mais avançados do que a formação continuada? Educação em serviço ${ }^{5}$ não possuiria ainda mais uma identificação com as orientações da OCDE e BIRD, caracterizando-se mais conservadora?

Um outro item sobre o qual nos propomos a dialogar com as autoras estaria no fato de apontarem os MP como improdutivos, alegando que estariam tirando os professores da Educação Básica ${ }^{6}$. Em nossa interpretação, sugerem que tal formação faria com que os mestrandos (uma vez formados) abandonassem a escola básica. Nesse sentido, elas não poderiam fazer essas interpretações generalizadoras, porque seria facilmente contestado ao olhamos a realidade de nosso próprio Programa (apresentado com mais amplitude à frente) que está longe de corroborar com tal ideia. É preciso ter em mente que o MP está espalhado em todo território Nacional e que as realidades são as mais variadas?.

\section{Refletindo outros pontos divergentes em relação ao "protagonismo controverso dos mestrados profissionais"}

Antes de prosseguirmos, vale ressaltar que o estudo de Rezende e Ostermann (2015) e Ostermann e Rezende (2015) é importante porque, além da iniciativa, nos instiga a pensar a própria pós-graduação de maneira geral e o papel dos MP dentro da realidade brasileira. E, ainda, vale dizer que a nossa posição não, necessariamente, vem defender os MP, mas buscar demonstrar que as críticas estejam em outros lugares ou em outras direções. Procuramos com isso evitar "comprar as brigas erradas" ou trabalhar em "caixas vazias" (BOURDIEU, 2002).

Para nós, a crítica aos MP não está, necessariamente, na direção proposta pelas professoras. Antes mesmo de qualquer desconstrução do MP, uma vez que já possui um bom percurso

\footnotetext{
${ }^{5}$ Educação em serviço comumente é uma proposta encontrada em artigos ligados à área de saúde e à área de administração (cf. NUÑEZ; LUCKESI, 1980). Não é escopo deste artigo analisar essa proposta, mas de problematizá-la enquanto uma saída para Educação Básica melhor do que os MP. Não podemos abrir mão de acompanhar o trabalho docente e reconhecer também que a formação acontece no ambiente de trabalho e que será producente não ocorrer somente em seus formatos tácitos e/ou espontâneos. Trabalho docente e formação no ambiente de trabalho são temas recorrentes na área de educação - em literatura relativamente antiga, é possível ver essa discussão, como em Candau (1997) -, mas, educação em serviço não! Tem carga ideológica que deixa dúvida quanto a uma ressignificação, semelhante a termos como pedagogia empresarial, capital humano, pedagogia das competências, pedagogia da fábrica, etc. Não vemos como defender educação em serviço a partir de uma pedagogia crítica.

${ }^{6}$ Não obstante, de imediato, esse mesmo raciocínio não valeria para o MA? Cogitamos que, se a ideia das autoras, em algum momento, era garantir ampliação do MA (em relação ao MP) defendendo que recebessem mais alunos, como responderiam a essa pergunta: quem retiraria mais professores da Educação Básica, o Mestrado Profissional ou o Mestrado Acadêmico?

${ }^{7}$ Retomando a clássica ilustração de Popper (1972), como não fomos nós que dissemos que "todos os cisnes são brancos", nossa refutabilidade pode se restringir a dizer que encontramos um "cisne negro" que seja.
} 
na pós-graduação brasileira, o mais interessante, em termos dialéticos, seria saber o que os MP atingiram, o que conquistaram.

Desse modo, gostaríamos de prosseguir nossa interpretação identificando mais complicadores na argumentação das autoras. Num determinado momento, o referido artigo apontou os MP como conteudistas, como pode ser visto no trecho que se segue:

Pela escolha da ordem desses elementos, podemos supor a ordem de importância dada pelos elaboradores aos tipos de formação propostos. A formação conteudista, típica do modelo de racionalidade técnica, é a primeira e será proporcionada por disciplinas obrigatórias opcionais. (REZENDE; OSTERMANN, 2015, p. 551).

Sabemos que, ao falar do caráter conteudista, as autoras tomam como referência o MP em Ensino de Física da Universidade Federal do Rio Grande do Sul (UFRGS). Entretanto, elas não limitam a análise à realidade à qual seus dados estão circunscritos, mas, segundo seus próprios termos, dizem que, a partir desta realidade, descreverão “[...] as características básicas dos cursos de MP em ensino de Ciências" (REZENDE; OSTERMANN, 2015, p. 551). O MP em Ensino de Física da UFRGS foi criado em 2002, serviu de modelo para outros tantos espalhados pelo Brasil. Ora, um dos aspectos que reforçaria o argumento do caráter conteudista dos MP está no perfil do corpo docente deste curso, que abrigaria professores da área dura da Física e não apresentaria um corpo docente mais interdisciplinar. Não é o caso, por exemplo, de nossa realidade, que conta com um corpo docente de formação bem diversificada. Valem dois questionamentos. Ainda que aceitássemos a afirmação de que os MP são conteudistas, por que não lutar por um currículo que não fosse? Se fôssemos traçar um paralelo aos Mestrados Acadêmicos, não diríamos que esses, tradicionalmente, não seriam ainda mais, conteudistas?

Prosseguindo com o diálogo, um outro aspecto que traz certo desconforto é a afirmação de que a obrigatoriedade dos "produtos educacionais" imprime um ranço tecnicista ao curso. Ainda que pudéssemos concordar com as autoras, os argumentos trazidos engendram uma contradição quando alegam que, por exemplo: "os produtos educacionais não representariam solução para os problemas da educação brasileira” (OSTERMANN; REZENDE, 2015, p. ii). Seria para tanto? O próprio documento da área de Ensino elaborado pela Capes orienta para que o produto seja algo vinculado à realidade do mestrando para que este possa vir a encontrar saídas para os impasses vividos: "O mestrando deve desenvolver um processo ou produto educativo e utilizá-los em condições reais de sala de aula ou de espaços não formais ou informais de ensino, em formato artesanal ou em protótipo" (CAPES, 2013b, p. 24-25). Não há em momento algum a pretensão de elaborar um produto que se pretende aplicável em todo o território nacional, ainda que acreditemos que as ideias possam ser trocadas e impulsionar soluções em outros cantos. Assim sendo, percebemos que há de imediato uma diferença de entendimento do papel dos produtos nos MP. Não depositamos nos produtos esse potencial abrangente e de cunho salvacionista da educação brasileira, até porque não o percebemos como a única contribuição prestada pelos MP. Os produtos educacionais possuiriam essa força "de solução para os problemas" educacionais do Brasil? Os MP poderiam assumir essa centralidade dentro de um projeto político mais amplo?

Outra questão a ser analisada é colocada no editorial escrito por elas: 
Além disso, conforme levantamento realizado por Rezende, Ostermann e Ferraz (2009), a produção nacional sobre o ensino de física, por exemplo, já é abundante de propostas de metodologias de ensino, desenvolvimento de experimentos para o laboratório didático e elaboração de materiais didáticos para a sala de aula, o que vem a tornar a produção dos mestrados profissionais como 'mais do mesmo'. (OSTERMANN; REZENDE, 2015, p. iii).

Seria crítica producente dizer que os MP só fazem mais do mesmo? Na verdade, essa crítica não seria para todas as modalidades da pós-graduação (para o MA, até mesmo para o Doutorado, e que isso viria de longa data)? Um pouco na direção do que diz R. Jacoby há um bom tempo: "Os textos acadêmicos de hoje frequentemente invocam para si uma ousadia e uma modernidade inéditas, mas ao mesmo tempo deixam quase sempre transparecer deferência e limitação, num estranho emaranhado de clichês e subserviências” (JACOBY, 2001, p. 141).

O mais do mesmo é peculiaridade exclusiva dos MP? Concordamos com Jacoby (2001), esse problema parece bem mais amplo e antigo.

Identificamos outro ponto divergente com as autoras quando disseram que:

O aspecto da formação individual está presente em todos os cursos de MP, a exemplo dos mestrados acadêmicos, centrados em defesas individuais e na formação individual do aluno. $O$ investimento na formação docente individual por meio dos cursos de MP tem, assim, pouco impacto sobre a qualidade da educação por deixar de captar uma dinâmica mais ampla e intencional do coletivo de professores a partir da escola (REZENDE; OSTERMANN, 2015, p. 554).

Embora elas tenham iniciado sobre um ponto para o qual convergimos, que o formato dos MP não se diferenciaria muito do MA porque dá aos professores a mesma trajetória individual, não vemos isso como o mais relevante. Um dos grandes problemas que identificamos dos MP não é mencionado, que seria levar a lógica de uma educação dual (as clássicas separações entre o propedêutico e o técnico, a insistente diferença entre a educação para os grupos mais abastados e a educação para o trabalhador) até o patamar da pós-graduação ${ }^{8}$. Restringiram-se

\footnotetext{
${ }^{8} \mathrm{Na}$ verdade, as duas autoras possuem um artigo em que iniciam as primeiras críticas aos Mestrados Profissionais, intitulado "Projetos de desenvolvimento e de pesquisa na área de ensino de ciências e matemática: uma reflexão sobre os mestrados profissionais" (OSTERMANN; REZENDE, 2009), por um caminho científico-político muito interessante. A crítica conseguiu mostrar que: (a) apesar da resistência da área de educação, os MP prosseguiram; (b) não seria fecundo o distanciamento que se poderia obter entre pesquisa e prática docente; (c) haveria realmente um ranço tecnicista em transpor a ideia dos mestrados profissionalizantes (da mesma forma que acontecia em outras áreas) para área de Educação; (d) os produtos educacionais considerassem referenciais teóricos densos sobre ensino-aprendizagem, etc. Terminaram afirmando que os MP não deveriam silenciar problemas mais abrangentes sobre Educação em Ciências ou da Educação em geral, ou seja, alcançaram uma crítica firme sobre os MP e sobre o lugar que potencialmente estavam ocupando, alertando até para seus limites. E naquele momento não sucumbiram em dizer que no lugar da formação continuada dos MP deveríamos pensar numa "Educação em Serviço" e nem generalizaram ao dizer que os MP afastam os professores da Educação Básica.
} 
à crítica da trajetória individual como sendo um dos grandes problemas do MP. No entanto, o que é mais indispensável aos MP (de Ensino, no caso)? Apresentarem-se como uma "formação continuada de forma coletiva" ou não perder de vista a reflexão do próprio trabalho docente?

Um outro ponto de discordância encontra-se nas colocações das autoras ao dizerem: “outro aspecto preocupante da formação docente em nível de MP é o destino dos egressos" (REZENDE; OSTERMANN, 2015, p. 555). Nessa parte, as autoras se ressentem pela migração dos mestrandos profissionais para o "Ensino Superior (privado, em geral) ou para os Institutos Federais de Educação, Ciência e Tecnologia (IFET)" (REZENDE; OSTERMANN, 2015, p. 555). Lamentam que os docentes tenham abandonado a escola que trabalhavam ao ingressar no mestrado, não problematizam que a saída dessa escola poderia estar ligada a muitos outros fatores, desde a precarização das condições de trabalho à desvalorização do magistério. Acabam por desconsiderar a livre escolha desses docentes. A possibilidade de sair da Educação Básica, proporcionada pelo Mestrado, pode sim ser a mais libertária para muitas situações. E, o mais importante, como veremos adiante (quadro 3), essa generalização é questionável, uma vez que constatamos em nossa realidade que a maior parte dos egressos do Mestrado Profissional em Ensino de Ciências (PROPEC-MP) do Instituto Federal de Educação, Ciência e Tecnologia do Rio de Janeiro (IFRJ) continuam na EB. E mais, quando elas não qualificam adequadamente essa migração da Educação Básica para o Ensino Superior ou para os IFET, indicam a possibilidade de uma incompreensão importante, porque ir para os IFET, grosso modo, não é sair, mas permanecer na Educação Básica (ainda que seja numa escola técnica federal).

Pensando na importância da Formação Continuada, seria mais pertinente uma crítica que demonstrasse que as tarefas atribuídas ao MP poderiam, sim, ser realizadas pelos clássicos Mestrados Acadêmicos, desde que obtivessem apoio, estrutura e orientações para isso. Entretanto, propor a "Educação em Serviço" em substituição ao MP (como se fosse uma relação trade-off) é um grande equívoco. Sem os devidos cuidados, sem a caracterização clara do que seja a "Educação em Serviço", pode haver um retrocesso maior. Hoje os MP são chancelados pelas Instituições de Ensino Superior. Como seria a situação da "Educação em Serviço"? A "Educação em Serviço" tem um apelo ainda mais imediatista, bem peculiar aos interesses do OCDE e do Banco Mundial (BIRD). (ALTMANN, 2002).

No fim das contas, existe uma forte contradição nos argumentos do artigo de Rezende e Ostermann (2015), pois, apesar do referencial teórico principal ter sido Acácia Kuenzer, acabaram aproximando-se muito do que propõe o BIRD. O trabalho de Helena Altmann aponta quais seriam os interesses e orientações do Bird:

O pacote de reformas educativas proposto pelo BIRD contém os seguintes elementos [...]: a) Prioridade depositada sobre a educação básica. b) Melhoria da qualidade (e da eficácia) da educação como eixo da reforma educativa. [...] c) Prioridade sobre os aspectos financeiros e administrativos da reforma educativa, dentre os quais assume grande importância a descentralização. d) Descentralização e instituições escolares autônomas e responsáveis por seus resultados. [...] (4) monitorar o desempenho escolar. e) Convocação para uma maior participação dos pais e da comunidade nos assuntos escolares. f) Impulso para o setor privado e organismos não governamentais como agentes ativos no terreno educativo, 
tanto nas decisões como na implementação. g) Mobilização e alocação eficaz de recursos adicionais para a educação como temas principais do diálogo e da negociação com os governos. h) Um enfoque setorial. i) Definição de políticas e estratégias baseadas na análise econômica (ALTMANN, 2002, p. 80 , grifos nossos).

O que destacamos acima foram os elementos que consideramos semelhantes ao que encontramos nos argumentos do artigo de Rezende e Ostermann (2015).

Quando elas indicaram que os MP fatidicamente fazem uma formação continuada precarizada, não consideraram dois elementos importantes. No primeiro, há uma linha tênue entre "formação continuada" e "formação inicial", que ocorre na pós-graduação, principalmente da área de ensino. Um docente que procura a pós-graduação (principalmente stricto sensu, seja qual for) não vem apenas pelos aspectos de seu trabalho (e nem recebe apenas isso do Programa), mas busca também uma formação que não encontrou na graduação. Não podemos esquecer que a pós-graduação, seja MP ou MA, oportuniza encontros com os pares e rica troca de experiências em realidades diversas. Em segundo lugar, se, para não sermos conteudistas, conforme as autoras afirmam, deveríamos sair de um curso regular stricto sensu para uma "Educação em Serviço", não tenderíamos a precarizar ainda mais a situação da formação de professores? Não estamos tratando de objetos diferentes? Ter uma política de formação continuada mais próxima do chão da escola se contrapõe à formação stricto sensu?

\section{Considerações de meio do percurso sobre a Crítica da Critica}

Vale fazermos, neste meio do caminho, algumas considerações. Nossa leitura infere que o artigo das autoras possui contradições significativas. Ainda que críticas - a escolha de Acácia Kuenzer como referência central demonstra essa pretensão à crítica -, as autoras acabaram ficando num patamar que talvez até embace mais do que ajude a entender os limites (e por que não, até as potencialidades) dos Mestrados Profissionais.

Destarte, a própria Associação Nacional de Pós-graduação e Pesquisa em Educação (ANPED), que outrora tinha uma crítica mais substancial aos Mestrados Profissionais, colocou em seu site o seguinte posicionamento do Fórum Nacional de Coordenadores de Programas de Pós-Graduação em Educação da ANPED (FORPRED):

Atualmente a área da Educação conta com 23 Cursos de Mestrado Profissional [em 2013] credenciados pela Capes, sendo a maioria em instituições públicas. O fato de os professores da Educação Básica (rede pública) que cursam MPs da área de Educação da rede pública não receberem bolsa, ao contrário de docentes de rede pública que cursam o MP oferecido pela Capes, cria uma diferenciação de tratamento para uma mesma categoria (ANPED, 2013).

Isso significa que até mesmo a FORPRED requalificou as críticas ao MP, pois chegaram a solicitar bolsas à Capes, em vez de propor seu fim. Algo bem diferente do posicionamento da Direção da ANPED, em junho de 2009, que escrevia: 
Assim, a ANPED ratifica sua posição histórica contrária à efetivação de mestrado profissional na área de educação, advogando a legítima expansão dos cursos stricto sensu, mestrado e doutorado, bem como de cursos lato sensu, por meio da consolidação de políticas de fomento à pós-graduação (ANPED, 2009).

Independentemente da ANPED ter modificado ou não sua percepção dos Mestrados Profissionais, temos dois pontos a considerar.

Primeiro, quem entra com a proposta de um Mestrado Profissional na Apresentação de Propostas para Cursos Novos (APCN ou, mais atualmente, pela plataforma Sucupira) da Capes, na área de Ensino ou Educação (conforme a classificação da Capes), certamente, sabe da posição histórica da ANPED. Dessa forma, o proponente de uma proposta de MP, quando sabedor dessa crítica, pode: (1) não implementar o curso; (2) ignorar a crítica e implementar; ou, (3) considerar a crítica, prosseguindo por um aperfeiçoamento (ainda que seja um caminho reformista). No segundo ponto, a ANPED se posicionou mais claramente contra no momento em que a Capes, por meio da Portaria Normativa de número 7, de 2009 (BRASIL, 2009), assumiu os MP definitivamente e ainda os igualou aos Mestrados Acadêmicos. Isso já ocorre há oito anos (em 2017), o que significa não ter alcançado êxito o pedido da direção da ANPED quando se colocou contrária à efetivação do mestrado profissional.

No Documento de Área de Educação de 2013 (CAPES, 2013a) já se contabilizavam 23 Mestrados Profissionais, enquanto no Documento de Área de Ensino (CAPES, 2013b) do mesmo ano contabilizavam-se 54 MP. A área de Educação acabou rendendo-se e aderiu aos MP. Não precisamos entrar no mérito de avaliar essa questão neste momento, mas podemos dizer que, no mínimo, a análise de hoje deve ser considerada em novas bases. O MP é uma realidade!’

No fim das contas, o artigo das professoras Rezende e Ostermann (2015) nos pareceu muito influenciado por um estudo sobre egressos do MP em Ensino de Física do Instituto de Física da Universidade Federal do Rio Grande do Sul (UFRGS), uma tese de doutorado intitulada: "Impacto do mestrado profissional em ensino de física da UFRGS na prática docente: um estudo de caso", da pesquisadora Eliane Dias Alvarez Schäfer (SCHÄFER, 2013).

O Mestrado Profissional em Ensino de Física (MPEF) da UFRGS foi fechado para turmas novas em maio de 2015, conforme o comunicado feito na página do Programa de Pósgraduação em Ensino de Física do Instituto de Física. Esse Mestrado foi criado em 2002 e em 13 anos (considerando a última turma) alcançou mais de 100 formandos (VEIT, 2015). Sem dúvida, uma história que contribuiu enormemente à pós-graduação, à área do ensino de física e à educação brasileira, de maneira geral. Nesse comunicado aparecem alguns dos motivos para o fechamento do curso, desde a falta de apoio da Capes, sem a contrapartida, até a demanda por uma estrutura ampliada advinda do convívio com o Mestrado Acadêmico e o Doutorado (que

\footnotetext{
${ }^{9}$ Em consulta efetuada na Plataforma Sucupira da Capes contabilizamos 40 cursos de mestrados profissionais registrados como em funcionamento na área de Educação e 73 cursos na área de Ensino. Disponível em: <https://sucupira.capes.gov.br/sucupira/public/consultas/coleta/programa/listaPrograma.jsf>. Acesso em: 1 abr. 2016.
} 
precisam estar em Programas diferentes do MP, com coordenações distintas, por exemplo). Do início do curso até seu fechamento definitivo obtiveram mais de 90 egressos: Dessa forma, vale uma questão, considerando as conclusões alcançadas pelo artigo das professoras: por que se deixou chegar a 90 egressos e 13 anos depois para compreender que o MP não cumpria seu papel?

A tese de doutorado da Schäfer (2013), que não é o escopo deste artigo, foi referência também para o artigo (REZENDE; OSTERMANN, 2015) e o editorial (OSTERMANN; REZENDE, 2015), que pesquisou exatamente os egressos do MPEF. Entre seus resultados, a tese tem esse destaque já em seu resumo:

Os achados evidenciam que as ações envolvidas na prática pedagógica dos alunos [do MPEF] desde a questão curricular, passando pelo planejamento, crenças e concepções estão impregnadas de elementos do racionalismo técnico. [...] Dessa forma, entende-se que a formação obtida parece não abalar o modelo da racionalidade técnica, que ainda está presente na prática docente da maior parte dos professores investigados (SCHÄFER, 2013, p. iv).

Não nos cabe discutir esse resultado, mas podemos fazer alguns questionamentos pertinentes à linha de argumentação que vimos realizando até aqui. O resultado advindo desse único caso (do MPEF) de um Programa de Mestrado Profissional, ainda que altamente importante, poderia ser generalizado para outros no Brasil? Um estudo publicado em 2013, onze anos após o início desse Programa de MP, realizado com vinte alunos (ainda cursando) e dois egressos poderia dar sustentação às conclusões que Rezende e Ostermann obtiveram em seu artigo e editorial? A tese de Schäfer (2013) apontou que os mestrandos e os egressos do MPEF não encontraram a formação mais adequada para enfrentar os desafios da escola básica. Não obstante, isso seria suficiente para desqualificar exclusivamente o MP ou seria um problema mais amplo, que vai da formação de professores (realizada nas Licenciaturas) até as pós-graduações, inclusive o MA, até o doutorado?

Mais uma vez, apontamos a necessidade de ampliação do foco, com a inclusão de outros elementos que devem compor a análise.

\section{Contribuindo com a nossa experiência}

Nosso curso criou mecanismos de acompanhamento de nossos egressos, desde questionários que são envidados periodicamente até a criação de uma página no Facebook para a manutenção de contatos. O questionário que enviamos, considerando este artigo, não se pretendeu exaustivo, serviu para realizar um breve levantamento com os nossos egressos, a fim de conhecer qual foi a sua trajetória ao término do curso. Neste levantamento buscou-se conhecer qual o destino profissional que cada um teve após o término do curso. Para sabermos, demos as opções observadas no Quadro 1, que mostra também o resultado da distribuição dos egressos do MP-Propec. 
Quadro 1. Egressos do MP-Propec em relação à permanência na Educação Básica

\begin{tabular}{|l|c|}
\hline Permaneço na Educação Básica & 23 \\
\hline $\begin{array}{l}\text { Permaneço na Educação básica, mas concilio atuan- } \\
\text { do em... }\end{array}$ & 2 \\
\hline Permaneci na Educação Básica entre 2 anos e 3 anos & 2 \\
\hline Na verdade, nunca estive na Educação Básica & 2 \\
\hline Não respondeu a esta questão específica & 1 \\
\hline
\end{tabular}

Fonte: elaborado pelos autores.

O contato inicial com os 71 egressos (considerando o ano de 2016) e o prosseguimento com as 30 entrevistas se deram por meio eletrônico. A pesquisa é de caráter descritivo, de levantamento (no caso de opinião). É direta, sem necessidade, para este caso, de qualquer técnica adicional porque não possui interesse de outras interpretações ou de apreender o não dito. Para melhor explicar, usamos Gil (2002, p. 42) como referência: "As pesquisas descritivas são [...] as que habitualmente realizam os pesquisadores sociais preocupados com a atuação prática. São também as mais solicitadas por organizações como instituições educacionais [...]. Geralmente assumem a forma de levantamento [...]". E as pesquisas de "levantamento", como define Gil (2002, p. 50):

As pesquisas caracterizam-se pela interrogação direta das pessoas cujo comportamento se deseja conhecer. Basicamente, procede-se à solicitação de informações a um grupo significativo de pessoas acerca do problema estudado para, em seguida, mediante análise quantitativa, obterem-se as conclusões correspondentes aos dados coletados.

O resultado alcançado, de forma imediata, já contradiz Rezende e Ostermann (2015), em relação à afirmação de que os MP retiram os professores da Educação Básica. De nossos egressos, 71 deles foram contatados e 30 foram entrevistados e, como pode ser constatado no Quadro 3, praticamente a totalidade disse continuar na Educação Básica. E o mais contundente: o Mestrado Profissional seria responsável pela saída apenas de 2 entre os 30 da Educação Básica (e esses dois ainda ficaram entre dois e três anos na EB).

Assim sendo, dos 30 entrevistados, 25 permanecem na EB. Isso é mais do que expressivo, é contundente. Podemos até dizer que praticamente a totalidade dos 30 entrevistados não saíram da Educação Básica por conta do Mestrado Profissional, considerando que dois deles nunca estiveram e um deles não respondeu (e os dois últimos, que definitivamente saíram, ficaram pelo menos dois anos).

Ainda que haja uma contra-argumentação à nossa, de que o encontrado acima foi uma experiência específica de um MP de um Instituto Federal (a nossa experiência), podemos derivar outros argumentos. Podemos inverter a problematização: nós questionamos a generalização das professoras Rezende e Ostermann, porque, quando elas dizem: “[...] ao passo que os MP 
servem para alavancar um pequeno grupo destes professores para atuarem nos IFET ou em instituições de Ensino Superior que representam, igualmente, o ingresso em outro nível social" (2015, p. 556), bastaria a nossa experiência, por si só, para relativizar a generalização (todos os cisnes não são brancos $)^{10}$.

Ademais, houve uma experiência específica que marcou as professoras, que parece ter também servido para a generalização que fizeram:

No estudo do curso de MP em ensino de Física da UFRGS [referem-se ao artigo de Shäfer e Ostermann, 2013], concluíram que a maioria dos professores egressos não permaneceu na escola em que lecionava ao ingressar no curso, tendo migrado para o Ensino Superior (privado, em geral) ou para os Institutos Federais de Educação, Ciência e Tecnologia (IFET). (REZENDE; OSTERMANN, 2015, p. 555).

O artigo das professoras Rezende e Ostermann (2015) não apresentou números gerais dos MP, não apresentou panorama algum a esse respeito - ainda que esteja pressuposto à rede do Observatório da Educação da Coordenação de Aperfeiçoamento de Pessoal de Nível Superior, mencionado no editorial (OSTERMANN; REZENDE, 2015) -, pareceu ter sido muito influenciado pela experiência específica do MP em ensino de Física da UFRGS. As autoras, apesar de mencionarem que, "Diante da variedade de MPs no ensino de ciências, resultantes dos processos de recontextualização, não há como generalizar e enquadrar todos eles nas afirmativas precedentes" (REZENDE; OSTERMANN, 2015, p. 554), não levam a termo o que sinalizam, não relativizando as afirmações feitas.

Quadro 2. Quanto o Mestrado Profissional influenciou em sua prática na Educação Básica

\begin{tabular}{|l|r|}
\hline Influenciou significativamente & 23 \\
\hline Não influenciou significativamente & 3 \\
\hline Deu retorno, mas não respondeu & 4 \\
\hline
\end{tabular}

Fonte: elaborado pelos autores.

Da totalidade dos entrevistados, somente 3 entenderam que o MP não ajudou em suas práticas. A seguir, selecionaram-se aleatoriamente alguns depoimentos dentre a totalidade de 30 . Em contrapartida, vale registrar que não faremos uma análise qualitativa desses depoimentos, uma vez que o mais interessante está nos quadros anteriores. Ainda assim, são importantes para ilustrar o quanto e de que forma os egressos continuaram na Educação Básica e o quanto o MP contribuiu significativamente, em vários aspectos, com mudanças na práxis docente.

\footnotetext{
${ }^{10}$ Referência à ideia de falseabilidade ou refutabilidade de Karl Popper (1972).
} 
Quadro 3. Depoimentos dos egressos do MP-Propec em relação à contribuição do Mestrado Profissional para a Educação Básica

\begin{tabular}{|c|}
\hline O mestrado influenciou significativamente em minha prática docente na Educação Básica, em relação aos aspectos... \\
\hline O Mestrado Profissional melhorou significativamente minha prática pedagógica e me abriu portas para o doutorado. \\
\hline $\begin{array}{l}\text { Me deu [sic] seguranç para inovar na sala de aula, com autonomia e conhecimento, além do livro didático. Me } \\
\text { permite [sic] fazer aulas experimentais, saída de campo, pedir tarefas para os alunos exercerem o protagonismo. } \\
\text { Enquanto professora, me sinto mais segura e criativa. }\end{array}$ \\
\hline $\begin{array}{l}\text { Permitiu que eu fizesse algumas aproximações com outras disciplinas, melhorou minha compreensão em situações de } \\
\text { educação ambiental e em relação a práticas para desenvolver projetos de alfabetização científica. }\end{array}$ \\
\hline $\begin{array}{l}\text { Apesar de sempre acreditar que a educação é algo mais que conteúdos isolados, o mestrado profissional me ajudou a } \\
\text { fundamentar tal posicionamento, tendo mais referências que sustentam esses argumentos. } \\
\text { 1- Imprimiu em minha atuação profissional uma postura investigativa, que me impele a indagar os motivos (teorias) } \\
\text { que me levam a agir desta ou daquela maneira; } \\
\text { 2- Desenvolveu em mim um compromisso muito maior com os registros do meu fazer pedagógico. Sempre busco deixar } \\
\text { subsídios que possam auxiliar a investigação de um pesquisador que venha a se interessar pelo trabalho nas séries } \\
\text { iniciais do Ensino Fundamental futuramente; } \\
\text { 3- Promoveu a valorização do conhecimento produzido no cotidiano da escola ao mesmo tempo que evidenciou a } \\
\text { relevância da teoria para fundamentar e atribuir valor científico a esse conhecimento. A descoberta do saber docente, } \\
\text { como um saber singular, trouxe a necessidade inadiável de aproximar a escola com a universidade em condição } \\
\text { paritária e complementar. }\end{array}$ \\
\hline $\begin{array}{l}\text { Ampliou minha visão de ensino e aprendiragem infuenciando práticas } \\
\text { pedagógicas e forma de avaliação. }\end{array}$ \\
\hline $\begin{array}{l}\text { - Passei a ter mais subsídios teóricos para o preparo de minhas aulas; } \\
\text { - Comecei a levar para sala de aula alguns questionamentos críticos para além das questões técnicas de minha } \\
\text { disciplina; } \\
\text { - Comecei a produحir trabalhos com os alunos que estimulam e interagem com diferentes tipos de inteligências; } \\
\text { - Realizo pesquisas com alunos que se relacionam diretamente com minha dissertação. }\end{array}$ \\
\hline $\begin{array}{l}\text { - Melhorou consideravelmente a minha forma de objetivar a pesquisa na prática; } \\
\text { - Me proporcionou [sic] uma qualidade melhor de escrita sobre a prática; } \\
\text { - Me levou [sic] a estar sempre conectada com instituiçôes e publicaçōes sobre prática docente e ensino de ciências; } \\
\text { - Como trabalho na educação básica, com crianças, minha visão sobre toda a educação básica, e não só o men } \\
\text { segmento de ensino, me proporciona [sic] um olhar mais amplo sobre todo o processo de ensino-aprendizagem nessa } \\
\text { área. }\end{array}$ \\
\hline
\end{tabular}

Fonte: elaborado pelos autores.

Os elementos possíveis de analisar nos depoimentos acima são muitos, mas não é exatamente o propósito deste trabalho. Poderíamos, por exemplo, tomar como hipótese de trabalho, por meio de procedimentos qualitativos de análise, um possível distanciamento entre os depoimentos dos professores e a real prática deles, um pouco como Schäfer (2013) fez em sua tese. Ou poderíamos optar por um caminho de problematização para dizer que os depoimentos não se diferenciariam muito de outro que fizesse uma pós-graduação qualquer, desde uma pós-lato até um Mestrado Acadêmico. Contudo, no fim, o que podemos dizer, é que esses egressos estão na Educação Básica de fato, estão com novas práticas e que o Mestrado Profissional (ainda que considerando trajetórias individualizadas, como ter o horizonte do 
doutorado, ou obter a participação em grupos de pesquisa, ou ainda perceber a melhora no Currículo Lattes, todas válidas) proporcionou a eles aspectos formativos que foram além da revisão de sua prática, o que, certamente, não possuíam antes, como: novos conhecimentos sobre abordagens didáticas e metodológicas; maior criticidade em relação à educação ambiental; consideração pelos aspectos de ensino-aprendizagem e pelas demandas dos alunos; utilização de recursos tecnológicos de forma mais ampliada; postura investigativa; apreensão de elementos teórico-conceituais e práticos em relação ao Ensino de Ciência; desenvolvimento de novos posicionamentos políticos entre outros.

\section{Considerações}

Apesar de todo nosso percurso para dizer que as críticas das professoras Rezende e Ostermann aos Mestrados Profissionais estiveram em lugares de que discordamos, não viemos para defender os MP integralmente. Na verdade, estamos mais próximos de outro artigo das professoras, intitulado: "Projetos de desenvolvimento e de pesquisa na área de ensino de ciências e matemática: uma reflexão sobre os mestrados profissionais" (OSTERMANN; REZENDE, 2009), em que elas, por um outro percurso: problematizaram a implementação dos MP na área de Educação; questionaram a concepção que está por detrás dessa política (da Capes); ensaiaram que o destino dos egressos poderia contemplar os interesses das Instituições de Ensino Superior privadas; criticaram o ranço tecnicista que poderia vir com os produtos educacionais (embora tenham apontado que pesquisas com maior apelo para reflexões sobre ensino-aprendizagem poderiam reverter isso); problematizaram a fronteira tênue entre "pesquisa e desenvolvimento"; questionaram a negligência que haveria para pensar outros caminhos importantes, como o lugar das licenciaturas etc.

As contradições dos Mestrados Profissionais (MP), especialmente dos Mestrados Profissionais em Rede, são enormes, mas algumas não são exclusivamente deles, mas das próprias políticas que comumente são impostas à Educação no Brasil, baseadas em imediatismo, massificação sem estrutura, urgência de números, priorização de setores em detrimento de outros, idiossincrasia dos gestores, pouco ou nenhum planejamento, proselitismo de alguns grupos, precarização do trabalho, aligeiramento, academicismo ${ }^{11}$, entre outros. Em muitas situações nos parece que esses elementos estão por detrás das propostas do MP, e por isso é realmente necessária uma vigilância permanente. Todavia, não vai ser propondo uma "Educação em Serviço" em substituição do que se supõe ser uma "formação continuada precarizada" dos MP, ou caracterizando de forma generalizada a formação dos mestrandos como sendo tecnicista,

\footnotetext{
${ }^{11}$ Em alguns momentos do artigo de Rezende e Ostermann (2015, p. 551) nos aproximamos fortemente das autoras: "O uso de novas tecnologias no ensino é mencionado, mas, novamente, essa demanda não parte da realidade escolar, ou da realidade do professor, mas, sim, de especialistas acadêmicos que julgam serem esses os elementos necessários para aprimorar a qualificação do docente e que, consequentemente, terão impacto na qualidade do Ensino Médio".
} 
ou ideologizando excessivamente o destino dos egressos, dizendo que estão se afastando da Educação Básica, ou mesmo hipostasiando o papel e alcance dos MP (como o de resolver o problema educacional brasileiro), que superaremos todos os desafios e inconsistências.

É importante somar os aspectos estruturais envolvidos e as concepções que embasam as propostas à conjuntura política que as envolve. A crítica que já existia na origem do MP já apontava seus limites, mas isso não foi suficiente para freá-lo. O que não houve para impedir seu processamento? Tudo foi negativo?

$\mathrm{Na}$ Educação (de forma lato, nas áreas de Educação e Ensino da Capes), aconteceu a revisão de muitos de seus elementos iniciais - em alguns Programas, o produto educacional foi aperfeiçoado, associado à dissertação, acataram-se percursos mais longos aos mestrandos de 24 para 30 meses, como forma de evitar aligeiramento, e ainda há uma luta por bolsas -, algo que talvez explique seu prosseguimento, apesar de tão criticado.

Claro que nada nos impede de retomar questionamentos de origem: por que não se incentivaram os tradicionais Mestrados Acadêmicos (MA), através de bolsas e outros investimentos, em vez de assumir o que hoje supostamente está delegado aos MP? Ou de considerar questionamentos permanentes: qual a concepção que há por detrás dos MP? Sendo possível manter elementos ainda mais críticos: com o MP, não se está mantendo a compreensão equivocada de escola dual na pós-graduação (com conteúdo propedêutico e pesquisa básica para um grupo, de um lado, enquanto para o outro, um conteúdo técnico e pesquisa aplicada)? E finalmente: queremos isso?

E os Mestrados Profissionais em Rede (MPR)? De que forma estão sendo construídos? Se tratar-se de uma proposta de ampliação da pós-graduação stricto sensu, como está sendo efetivado e liderado? Por quais grupos? É fácil identificar seu proselitismo, a política idiossincrática? Possui estrutura adequada? E novamente: queremos isso?

Por tudo isso terminamos este trabalho dizendo que a análise conjuntural é tão importante quanto a estrutural. Quais lutas seriam mais producentes? O que já perdemos? O que há ainda para se lutar? Ainda há tempo de impedir o avanço dos MPR (caso os vejamos como improducentes)? Não seria a luta por bolsas para os MP o mais importante a ser considerado? Perguntas a que precisamos responder coletivamente, porque é pela compreensão de grupo, através do debate, que não somente responderemos às indagações, mas marcaremos posicionamentos ${ }^{12}$.

Importante frisar que analisar conjunturalmente não significa perder princípios, algo que nos últimos tempos tem sido muito confundido. Precisamos rever a pós-graduação brasileira. Aqui, por enquanto, falamos das áreas de Educação e Ensino, que no Brasil são separadas e já revelam nossas esquizofrenias. Nossos gestores costumam oscilar entre a pressa de melhorar os números e a falta de apoio para o que já temos, exigindo-nos qualidade através de tensos processos avaliativos. Mais importante do que propormos soluções mirabolantes ou impormos

\footnotetext{
${ }^{12} \mathrm{O}$ doutorado profissional, por exemplo, será a confirmação de uma precarização? Devemos lutar contra sua implantação? Não obstante, uma vez implantado (ou imposto), como se travarão as lutas para que não reforce o dualismo na pós-graduação? As questões de conjuntura não precisam rivalizar com as de estrutura, mas são dimensões da luta possível.
} 
nossa visão de educação (idiossincrasia comum aos nossos gestores e recorrente nos finais dos artigos) é apoiar e permitir que os Programas de Pós-graduação correspondam às expectativas regionais, missão e aos objetivos propostos em seu projeto político pedagógico, para acolher com mais qualidade as pessoas advindas das mais diversificadas realidades. Isso será bem melhor do que impor uma formação acelerada e massificante, através de políticas provisórias e ampliações sem estrutura. Sempre que qualquer proposta de pós-graduação corresponder a essa precarização e mediocrização, deve ser combatida firmemente. No fundo, essa é a crítica que une a todos nós, a mesma a que certamente as professoras Rezende e Ostermann se propuseram e que também nos propomos, ainda que de outra forma...

\section{Referências}

ALTMANN, H. Influências do Banco Mundial no projeto educacional brasileiro. Educação e Pesquisa, São Paulo, v. 28, n. 1, p. 77-89, 2002. Disponível em: <https:/ /doi.org/10.1590/ S1517-9702200200010000>. Acesso em: 5 fev. 2018.

ANPED. Carta da direção da ANPED sobre a portaria que regulamenta os mestrados profissionais. [2009]. Disponível em: <http://www.mped.uneb.br/wp-content/ uploads/2017/05/anexo7_carta_Anped_portariaMP2009.pdf>. Acesso em: 5 fev. 2018.

. Mestrado profissional e professores da educação básica: ministro Mercadante instituiu grupo de trabalho no MEC a partir de solicitação da ANPEd. 2013. Disponível em: $<$ http:/ / www.anped.org.br/news/mestrado-profissional-e-professores-da-educacao-basicaministro-mercadante-instituiu-grupo-de>. Acesso em: 5 fev. 2018.

BOURDIEU, P. Bourdieu entrevistado por Maria Andréa Loyola. Rio de Janeiro: EdUerj, 2002.

Escritos da educação. Petrópolis: Vozes, 1998.

BRANDÃO, M. A.; DECCACHE-MAIA, E.; BOMFIM, A. M. Os desafios da construção de um mestrado profissional: um panorama de sete anos. Polyphonía, Goiânia, v. 24, n. 2, p. 319-337, 2013. Disponível em: <https://www.revistas.ufg.br/sv/article/ view/37941/19059>. Acesso em: 5 fev. 2018.

BRASIL. Ministério da Educação. Portaria normativa n 7, de 22 de junho de 2009. Dispõe sobre o mestrado profissional no âmbito da Fundação Coordenação de Aperfeiçoamento de Pessoal de Nível Superior - CAPES. Diário Oficial da União, Brasília, n. 117, p. 31, 2009. Seção 1.

CANDAU, V. M. (Org.). Magistério: construção cotidiana. Petrópolis: Vozes, 1997. 
A crítica da crítica dos mestrados profissionais: ...

CAPES. Avaliação trienal 2013: documento de área 2013: área de avaliação: educação.

2013a. Disponível em: <https://www.capes.gov.br/images/stories/download/

avaliacaotrienal/Docs_de_area/Educação_doc_area_e_comissão_21out.pdf>.Acesso em: 5 fev. 2018.

Avaliação trienal 2013: documento de área 2013: área de avaliação: ensino. 2013b. Disponível em: <https://pos.cepae.ufg.br/up/480/o/Ensino_doc_area_e_comissao.pdf >. Acesso em: 5 fev. 2018.

- Portaria $n^{\circ} 080$, de 16 de dezembro de 1998. Dispõe sobre o reconhecimento dos mestrados profissionais e dá outras providências. Diário Oficial da União, Brasilia, p. 14, 11 jan. 1999. Seção 1. Disponível em: <https://ebape.fgv.br/sites/ebape.fgv.br/files/portaria_ capes_080.pdf>. Acesso em: 5 fev. 2018.

GIL, A. C. Como elaborar projetos de pesquisa. 4. ed. São Paulo: Atlas, 2002.

HOUAISS, A. Grande dicionário Houaiss da língua portuguesa. Disponível em: <houaiss.uol.com.br>. Acesso em: 15 abr. 2016.

JACOBY, R. O fim da utopia. Rio de Janeiro: Record, 2001.

NUÑEZ, R. S.; LUCKESI, M. A. V. Educação em serviço: desenvolvimento em recursos humanos em enfermagem. Revista Brasileira de Enfermagem, Brasília, v. 33, n. 1, p. 54-80, 1980. Disponível em: < https://doi.org/10.1590/0034-716719800001000006>. Acesso em: 5 fev. 2018.

OSTERMANN, F; REZENDE, F. Os mestrados profissionais em ensino das ciências da natureza no Brasil. Ciência \& Educação, Bauru, v. 21, n. 3, p. i-iii, 2015. Disponível em: $<$ https://doi.org/10.1590/1516-731320150030001>. Acesso em: 4 fev. 2018.

. Projetos de desenvolvimento e de pesquisa na área de ensino de ciências e matemática: uma reflexão sobre os mestrados profissionais. Caderno Brasileiro de Ensino de Física, Florianópolis, v. 26, n. 1, p. 66-80, 2009.

POPPER, K. A lógica da pesquisa científica. São Paulo: Cultrix, 1972.

REZENDE, F; OSTERMANN, F. O protagonismo controverso dos mestrados profissionais em ensino de ciências. Ciência \& Educação, Bauru, v. 21, n. 3, p. 543-558, 2015. Disponível em: <https://doi.org/10.1590/1516-731320150030002>. Acesso em: 4 fev. 2018.

ROÇAS, G. et al. O mestrado profissional em ensino de ciências do Instituto Federal de Educação, Ciência e Tecnologia do Rio de Janeiro: o desafio do ensino de pós-graduação na região da Baixada Fluminense do Rio de Janeiro. Ensino, Saúde e Ambiente, Rio de Janeiro, v. 4, n. 2, p. 2-16, 2011.

SCHÄFER, E. D. A. Impacto do mestrado profissional em ensino de física da UFRGS na prática docente: um estudo de caso. 2013. Tese (Doutorado em Ensino de Física) - Instituto de Física, Universidade Federal do Rio Grande do Sul, Porto Alegre, 2013. Disponível em: <http://hdl.handle.net/10183/78481>. Acesso em: 5 fev. 2018. 
Bomfim, A. M.; Vieira, V.; Deccache-Maia, E.

SCHÄFER, E. D. A.; OSTERMANN, F. Autonomia profissional na formação de professores: uma análise de entrevistas realizadas num mestrado profissional em ensino de física. Revista Electrónica de Enseñanza de las Ciencias, Vigo, v. 12, n. 2, p. 287-312, 2013. Disponível em: <http://reec.uvigo.es/volumenes/volumen12/reec_12_2_4_ex696. $\mathrm{pdf}>$.

\section{VEIT, E. A. Comunicado sobre a não abertura de novas turmas no mestrado} profissional em ensino de física da UFRGS. 2015. Disponível em: < http:/ / www.if.ufrgs. br/ppgenfis/arquivos_upload/comunicado_maio_2015_ppgenfis.pdf > . Acesso em: 5 fev. 2018. 